\title{
A LIBERDADE DE ENSINO, A PLURALIDADE DE CONCEPÇÕES PEDAGÓGICAS E O CONTEÚDO POLÍTICO DA EDUCAÇÃO
}

\section{THE FREEDOM OF TEACHING, THE PLURALITY OF PEDAGOGICAL CONCEPTIONS AND THE POLICY CONTENT OF EDUCATION}

\author{
Marcos Rohling ${ }^{1}$ \\ Ione Ribeiro Valle ${ }^{2}$
}

\section{RESUMO}

Objetiva-se, neste texto, discutir os princípios constitucionais educacionais, nomeadamente, o da liberdade de ensino e o da pluralidade de ideias e concepções pedagógicas, e sua relação com o conteúdo político da educação a partir da Constituição de 1988. Com base na análise bibliográfica e documental, o artigo será, assim, estruturado em quatro partes: (i) na primeira parte, busca-se discutir a educação como um direito de natureza social que guarda conexão com as diferentes liberdades fundamentais; (ii) na segunda parte dando prosseguimento, discorre-se sobre os princípios constitucionais educacionais, sobretudo, a respeito da liberdade de ensino e do pluralismo de concepções e ideias pedagógicas; (iii) na terceira parte, explora-se o conteúdo político da educação nacional a partir da Constituição de 1988; e, (iv) finalmente, na quarta parte, como desdobramento desta última, relaciona-se o conteúdo político da educação com a liberdade de ensino. Com isso, espera-se, de um lado, evidenciar que a liberdade de ensino e a pluralidade de concepções pedagógicas são imperativos democráticos e, de outro, defender que, no interior das instituições de ensino, não sejam omitidas as discussões críticas a respeito da cultura política necessárias à participação dos educandos na vida pública como cidadãos.

Palavras-chave: Liberdade. Ensino. Concepções Pedagógicas. Constituição Federal.

\begin{abstract}
The objective of this article is to discuss the constitutional principles of education, namely, the freedom of teaching and the plurality of pedagogical ideas and conceptions, and their relationship with the political content of education from the 1988 Constitution. Based on the bibliographic and documentary analysis, the article will be structured in four parts: (i) in the first part, it is sought to discuss education as a social right that is connected to the different fundamental freedoms; (ii) in the second part, giving continuation, it is argued on the constitutional principles of education, above all on the freedom of teaching and the pluralism of pedagogical conceptions and ideas; (iii) in the third part, it is discussed the political content of national education as of the 1988 Constitution; and, (iv) finally, in the fourth part, as a result of the latter, is related to the political content of education with the freedom of teaching. With this, it is expected, on the one hand, to show that the freedom

\footnotetext{
${ }^{1}$ Doutor em Educação (UFSC), Mestre em Filosofia (UFSC), Graduado em Filosofia (UFSC), Graduado em Direito (UNOESC) e Professor de Filosofia e Ciência Humanas do Instituto Federal de Educação, Ciência e Tecnologia Catarinense (IFC), Campus Videira. Afiliação: Instituto Federal de Educação, Ciência e Tecnologia Catarinense (IFC). Lattes:http://lattes.cnpq.br/1426156565430729 ORCID:http://orcid.org/0000-0002-83793581. E-mail: marcos_roh@yahoo.com.br

${ }^{2}$ Doutora em Ciências da Educação pela Université René Descartes - Paris V - Sorbonne. Professora associada do Centro de Ciências da Educação da Universidade Federal de Santa Catarina (UFSC). Bolsista de produtividade em pesquisa do Conselho Nacional de Desenvolvimento Científico e Tecnológico (CNPq). Afiliação:Universidade Federal de Santa Catarina (UFSC). Lattes:http://lattes.cnpq.br/4490226468776272 ORCID:http://orcid.org/00000001-7496-3959. E-mail:ione.valle@ufsc.br
} 
of teaching and the plurality of pedagogical conceptions are democratic imperatives and, on the other, to defend that, within educational institutions, are not omitted the critical discussions about the political culture necessary for the participation of students in public life as citizens.

Keywords: Freedom. Teaching. Pedagogical Conceptions. Federal Constitution.

\section{INTRODUÇÃO}

Recentemente, no Brasil, no meio político e em diversos segmentos sociais, deu-se início a uma discussão bastante profunda a respeito da liberdade e das concepções pedagógicas docentes. Questiona-se, em muitos desses espaços sociais, se, de fato, deveria existir algum limite à liberdade de ensino em face das diferentes concepções morais e religiosas que têm os pais, os responsáveis e os próprios alunos, de forma a se estabelecer uma educação "neutra". A ideia básica de programas como esses é o cerceamento da liberdade de ensino em vista da "instrumentalização do ensino para fins políticos, ideológicos e partidários" por parte dos professores - como é o caso do projeto Escola sem Partido (NAGIB, 2019).

No centro dessa disputa, está o princípio constitucional da educação, o princípio da liberdade de ensino (art. 206, II, Constituição Federal de 1988; art. 3, II, Lei de Diretrizes e Bases da Educação Nacional de 1996$)^{3}$, que confere ao professor e ao aluno a liberdade para aprender, ensinar, pesquisar e divulgar o pensamento, a arte e o saber. Também, incidentalmente, isto é, como desdobramento dessa disputa, aparece o princípio da pluralidade de ideias e concepções pedagógicas (art. 206, III, CRFB/88; art. 3, III, LDBEN/96) - e, também, a coexistência de instituições públicas e privadas de ensino - que preceitua que os sistemas de ensino e as instituições educacionais devem respeitar as diferentes concepções filosóficas, teóricas e pedagógicas que os docentes, os discentes, os pais e as próprias escolas possam vir a ter. Fica claro, por isso, que essa disputa tem desdobramentos relevantes para a seara jurídica e educacional concomitantemente.

Com efeito, a despeito dessas questões, abordar-se-á, neste texto, não propriamente se há ou não a possibilidade de se avançar nessa temática, mas, antes, a partir estritamente da CRFB/88, a própria natureza política da educação nacional. Com isso, quer-se defender a tese de que a educação tem um conteúdo político, de forma a que, tanto o princípio da liberdade de ensino quanto o da pluralidade de ideias e concepções pedagógicas estão politicamente contornados e determinados. Trata-se, assim, de afirmar que qualquer pretensão de afastamento da educação de discussões

\footnotetext{
3 Doravante, usar-se-á as siglas CRFB/88 para Constituição da República Federativa do Brasil de 1988 e LDBEN/96 para Lei de Diretrizes e Bases da Educação Nacional de 1996.
} 
políticas carece de validade em vista da ordem constitucional democrática vigente, dada nos termos da Lei Maior. ${ }^{4}$

Tendo-se um tal propósito em perspectiva, intenta-se, neste artigo, a partir da análise bibliográfica e documental, discorrer sobre os princípios constitucionais educacionais da liberdade de ensino e da pluralidade de ideias e concepções pedagógicas e o seu conteúdo político nos termos da CRFB/88. Para tanto, o texto será arvorado do seguinte modo: na primeira parte, apresenta-se a educação, no quadro constitucional como um direito de natureza social que, no entanto, guarda relação com as diferentes formas de liberdades fundamentais; em seguida, procura-se discorrer sobre os princípios constitucionais educacionais, com particular atenção o da liberdade de ensino e o pluralismo de concepções e ideias pedagógicas; na terceira parte, por sua vez, explora-se o conteúdo político da educação nacional, dado especialmente nos termos dos art. $1^{\circ}$ e $3^{\circ}$ da CRFB/88; e, finalmente, em quarto lugar, como desdobramento desse último, explora-se o conteúdo político da liberdade de ensino, no qual se defende que, no interior das instituições de ensino, não se preceda das discussões críticas a respeito da cultura política necessária à participação dos educandos na vida pública como cidadãos. Espera-se, assim, que fique evidente que a educação nacional, muito embora respeite as diferentes concepções pedagógicas bem como a liberdade de ensino, é comprometida com valores políticos que demandam compromissos por parte dos atores da educação.

\section{A EDUCAÇÃO: UM DIREITO SOCIAL E SUA RELAÇÃO COM A LIBERDADE}

Ao longo do século XX, a educação consolidou-se como um direito que não pode ser negligenciado: o art. 26, da Declaração Universal dos Direitos Humanos, de 1948, rubrica que toda pessoa tem direito à instrução. No âmbito da CRFB/88, o direito à educação deve ser concebido como um instrumento republicano de inclusão social, de tal modo que, em razão da amplitude e da forma como aparece no texto constitucional, ela é concebida como um direito fundamental assegurado a todos os brasileiros indiscriminada e universalmente (RODRIGUES \& MAROCCO, 2014, p. 214-5).

Antes de se salientar o caráter social do direito à educação, tal como consignado pela CRFB/88, importa apontar para o fato de a educação estar em estreita relação com a liberdade, nos

\footnotetext{
${ }^{4}$ Alerta-se para um ponto: não é o escopo deste artigo avançar na direção do exame das políticas públicas da educação, nem, tampouco, considerar sociologicamente o processo de formação das leis - certamente, algo extremamente valioso e enriquecedor. $\mathrm{O}$ que se pretende, algo seguramente mais modesto, é discutir o horizonte teórico segundo o qual a educação nacional tem, intrinsecamente, uma dimensão política dada nos termos dos fundamentos, objetivos, direitos e garantias fundamentais individuais e sociais. Trata-se, assim, de uma chave de leitura, desde a perspectiva constitucional, e, portanto, básica quanto ao papel fundante na hierarquia das leis, que determina o modo como todas as demais leis devem ser interpretadas, particularmente da educação.
} 
termos da sua vinculação com os direitos individuais civis e políticos; isto é, sem a educação, muitos dos direitos e liberdades fundamentais ficariam vazios e seriam obsoletos. Neste sentido, o artigo $5^{\circ}$ estabelece uma variedade abrangente de direitos e liberdades fundamentais, entre os quais os incisos I, II, IV, VI, VII, VIII, IX, além do próprio caput, tem uma relação direta com a educação. Particularmente, neste artigo, observa-se nominalmente os seguintes temas que se espraiam à educação: “[...] igualdade jurídica entre o homem e a mulher, a liberdade de consciência e de expressão, a liberdade de associação, a condenação a todo tipo de maus-tratos e a condenação ao racismo como crime inafiançável" (CURY, 2000, p. 19).

Deste ponto de vista, no exercício do direito à educação, esses outros direitos também se fazem presentes, uma vez que não podem ser dissociados, como grande princípio da liberdade, por exemplo, da liberdade de pensamento e da liberdade de consciência e de expressão - que são associados aos princípios constitucionais educacionais. De certo modo, o exercício dessas liberdades fundamentais reflete-se na prática da educação como atividade coletiva. Em relação a isso, duas considerações devem ser feitas: (i) a primeira delas diz respeito ao fato de que a educação, como aponta o artigo 208 da CRFB/88, é um direito público subjetivo - nesse particular, todo cidadão tem a prerrogativa, aqui de forma individual, inclusive, de requerer o direito à educação -; e (ii) a CRFB/88 prevê medidas para assegurar o exercício desses direitos e liberdades fundamentais. ${ }^{5}$

Não obstante, a educação é tratada ao longo do texto constitucional como um direito social, o que indica seu status, em termos de direitos e garantias fundamentais, conforme reza um dos seus artigos: "art. $6^{\circ}$. São direitos sociais a educação, a saúde, a alimentação, o trabalho, a moradia, o lazer, a segurança, a previdência social, a proteção à maternidade e à infância, a assistência aos desamparados, na forma desta Constituição" (BRASIL, 1988).

A este respeito, já se sabe que, em geral, os direitos sociais são decorrentes, filosófica e juridicamente, dos direitos humanos de segunda geração, os quais têm em vista assegurar a igualdade - isto é, sem eles, as liberdades garantidas resultariam vagas, formais e imprecisas, de vez que criam as condições mais propícias para que se tenha o exercício efetivo das liberdades fundamentais. Mas a visão de que os direitos sociais são direitos humanos de segunda geração não é a única forma que se tem de compreendê-los. Nesse sentido, Sarlet (2012) prefere o entendimento segundo o qual não se fala de gerações, tendo-se em conta que, desse ponto de vista, poder-se-ia hierarquizá-los, mas, em vez disso, nomina-os em termos de dimensões: os direitos sociais seriam direitos humanos de segunda dimensão, pois que não estão numa posição superior ou inferior

\footnotetext{
${ }^{5}$ Destaca-se, especialmente, o mandado de injunção, previsto no inc. LXXI, do art. $5^{\circ}$, in verbis "LXXI - concederse-á mandado de injunção sempre que a falta de norma regulamentadora torne inviável o exercício dos direitos e liberdades constitucionais e das prerrogativas inerentes à nacionalidade, à soberania e à cidadania". O mandado de injunção refere-se à proteção de direito ou liberdade, uma vez que inexista norma que discipline o seu exercício.
} 
àqueles de primeira dimensão. De modo mais particular, Sarlet vincula a compreensão dos direitos fundamentais a uma nova classificação, mais próximas ao constitucionalista Jellinek e ao filósofo e teórico do direito Alexy, nos seguintes termos: direitos de defesa e direitos sociais prestacionais. Nesse sentido, para Sarlet,

[...] enquanto os direitos de defesa se identificam por sua natureza preponderantemente negativa, tendo por objeto abstenções do Estado, no sentido de proteger o indivíduo contra ingerências na sua autonomia pessoal, os direitos sociais prestacionais têm por objeto conduta positiva do Estado (ou particulares destinatários da norma), consistente numa prestação de natureza fática. Enquanto a função precípua dos direitos de defesa é a de limitar o poder estatal, os direitos sociais (como direitos a prestações) reclamam uma crescente posição ativa do Estado na esfera econômica e social. Diversamente dos direitos de defesa, mediante os quais se cuida de preservar e proteger determinada posição (conservação de uma situação existente), os direitos sociais de natureza positiva (prestacional) pressupõem seja criada ou colocada à disposição a prestação que constitui seu objeto, já que objetivam a realização da igualdade (SARLET, 2001, p. 261).

Como se percebe, os direitos sociais requisitam uma presença ativa de financiamento e ativos econômicos para serem realizados. Essa posição é endossada pelo atual ministro do STF, o jurista Alexandre de Morais. Para ele,

Direitos Sociais são direitos fundamentas do homem, caracterizando-se como verdadeiras liberdades positivas, de observância obrigatória em um Estado Social de Direito, tendo por finalidade a melhoria das condições de vida aos hipossuficientes, visando à concretização da igualdade social, e são consagrados como fundamentos do Estado democrático, pelo art. $1^{\circ}$, IV, da Constituição Federal (MORAES, 2002, p. 202).

Dentro da visão em apreço, os direitos sociais traduzem-se em prestações positivas a serem ofertadas pelo Estado aos habitantes de seu território, "especialmente aos mais fracos e, normalmente mais numerosos, com o objetivo de diminuir as desigualdades sociais através da oferta de oportunidades para um número cada vez maior de cidadãos" (MOTTA, 1997, p. 155). Deveras, os direitos sociais elencados no artigo $6^{\circ}$, como se pode perceber, estão consubstanciados em normas principiológicas a serem cumpridas conforme as circunstâncias fáticas e a estrutura jurídica existentes, consoantes à essencialidade para a proteção da dignidade humana e para a promoção de condições dignas de existência (NOVELINO, 2016, p. 466).

Mas há outras implicações relevantes aqui: a educação é vista como um direito social, o que implica que o Estado deva oferecê-la a todos, como um dever correspondente. Ocorre que a responsabilidade pela educação foi dividida entre a família e a sociedade, de forma genérica. A consequência aqui está relacionada à competência legislacional em matéria educacional. Sobre isso, é pertinente dizer que compete privativamente à União legislar sobre as diretrizes e as bases da 
educação nacional, conforme indica o inciso XXIV, do artigo $22 .{ }^{6}$ Trata-se de competência privativa da União sobre a legislação das leis de caráter geral sobre a educação. ${ }^{7}$

Entendendo a educação como um direito social que, a um só tempo, é relacionada a liberdade, porquanto ser essencial para a realização e concretização das mesmas, e ter natureza social, conquanto não ser realizada de forma individual, o constituinte estabeleceu que ela deverá ser realizada consoante princípios. De fato, o texto constitucional previu uma série de princípios que deverão nortear a educação regular praticada no território nacional, seja em instituições públicas, seja em instituições particulares de ensino. Sobre isso, tratar-se-á na seção seguinte.

\section{OS PRINCÍPIOS CONSTITUCIONAIS EDUCACIONAIS}

Baseando-se na interpretação que Anísio Teixeira faz da pedagogia de Dewey, José Afonso da Silva defende que a concepção de educação agasalhada pela CRFB/88, ao declarar que ela é um direito de todos e um dever do Estado, é justamente aquela que a concebe como um processo de reconstrução da experiência e, portanto, como um atributo da pessoa humana. E, nesse sentido,

Tal concepção importa [...] em elevar a educação à categoria de serviço público essencial que ao Poder Público impende possibilitar a todos, daí a preferência constitucional pelo ensino público, pelo que a iniciativa privada, nesse campo, embora livre, é, no entanto, meramente secundária e condicionada (SILVA, 2014, p. 852).

O constitucionalista tem em vista a passagem em que Anísio Teixeira, em A Educação não é Privilégio (1971), explica que se o propósito é que a educação seja obrigatória, gratuita e universal, então, apenas o Estado deveria poder ministrá-la, vez que se asseguraria que não fosse privilégio de quem tivesse posses ou fosse protegido, agindo mais na intensificação das desigualdades sociais do que na sua remoção. Além disso, a educação, através da escola pública para todos, não poderia ser encarada como benevolência de uma classe dominante, mas, e isso é de absoluta importância, como

\footnotetext{
${ }^{6}$ In verbis: "Art. 22. Compete privativamente à União legislar sobre: [...] XXIV - diretrizes e bases da educação nacional" (BRASIL, 1988).

${ }^{7}$ Sobre o artigo 22, importa dizer que, no caso da competência legislativa privativa, a União pode delegar a competência aos Estado e Distrito Federal, o que se dá através de lei complementar, conforme preceitua o parágrafo único desse mesmo artigo. Sobre a possibilidade de conflito, ou mesmo confusão no que se refere à distribuição de competências, Silva (2014, p. 507-8) o seguinte: “A legislação concorrente da União sobre as matérias indicadas supra se limitará a estabelecer normas gerais. Nisso a Constituição foi, às vezes, redundante. Por exemplo, no artigo 22, XXIV, da como privativo da União legislar sobre diretrizes e bases da educação nacional, enquanto, no artigo 24, IX, combinado com o $§ 1^{\circ}$, declara caber-lhe legislar sobre normas gerais de educação. Não há nisso incoerência, como pode parecer. Legislar sobre diretrizes e bases da educação nacional e sobre normas gerais de educação somam, no fundo, a mesma coisa. A tradição arrastou os educadores da Constituinte a manter a regra que vem de 1946, que dava competência à União, para legislar sobre diretrizes e bases da educação nacional, mas também não poderiam deixar de incluir na competência comum legislar sobre educação, situação em que a União só tem poderes para fixar normas gerais. Tudo somado, dá na mesma, com um dispositivo a mais sem necessidade".
} 
direito de todos quantos vivem no país, especialmente, das classes trabalhadoras, geralmente submetidas às privações de acesso à formação e à educação (TEIXEIRA, 1971, p. 54).

Com efeito, o legislador constitucional entende que a educação, como direito de todos e dever do Estado e da Família, deve ser promovida e incentivada por ele, Estado, com a colaboração da sociedade, tendo por mote: (i) o pleno desenvolvimento da pessoa; (ii) o seu preparo para o exercício da cidadania; e (iii) a sua qualificação para o trabalho. Tem-se, assim, in verbis: “Art. 205. A educação, direito de todos e dever do Estado e da família, será promovida e incentivada com a colaboração da sociedade, visando ao pleno desenvolvimento da pessoa, seu preparo para o exercício da cidadania e sua qualificação para o trabalho" (BRASIL, 1988). Sobre a explicitação desse princípio, que é posteriormente retomado pela LDBEN/96, Cury compendia que a pessoa, a cidadania e o trabalho são três conceitos que sintetizam os fins da educação e até mesmo da ordem social. ${ }^{8}$ Para ele,

A pessoa é mais do que um sujeito jurídico na medida em que inclui o indivíduo singular (singulus), a sua inserção no social (socius), da qual o trabalho é condição do produzir e do reproduzir da existência social (faber), e o participante ativo nos destinos de sua sociedade (civis). A noção de pessoa inclui também as dimensões da afetividade e da arte (CURY, 2000, p. 28).

Daí deriva a noção de que a educação deve estar voltada ao pleno desenvolvimento da pessoa, em cujo processo se encontram, especialmente, a preparação essencial para o exercício ativo da cidadania e a qualificação para o mundo do trabalho. ${ }^{9}$ É um dado interessante a se observar a triangulação em que estão afixados os fins: em primeiro lugar, tem-se a pessoa humana; em segundo, a cidadania e, por fim, a qualificação para o trabalho. Ela parece sugerir uma ordem de importância a ser levada em conta pelos poderes públicos na efetivação do sistema educacional e na realização dos direitos educacionais. Como advogam Rizzi, Gonzalez e Ximenes (2011, p. 28):

\footnotetext{
${ }^{8}$ É necessário fazer uma distinção preliminar e funcional nesse tópico, notadamente, aquela entre princípios, fins e objetivos - evidentemente, sem adentrar na querela filosófica do direito sobre a natureza e o papel dos princípios na teoria constitucional e jurídica. Nesse sentido, em que pese existir, no âmbito filosófico-jurídico, uma diversidade de teorias sobre a natureza e o papel dos princípios - veja-se, por exemplo, em primeiro plano, Alexy e Dworkin, e, num segundo, Rawls e Habermas - entender-se-á que o papel dos princípios é aquele de constituirse em mandamentos básicos que norteiam a elaboração das leis e a aplicação do direito, sobretudo quando existir alguma lacuna. Os fins, por sua vez, compreendem o significado de algo ao qual se dirige um processo até ser acabado, isto é, a direção para a qual converge em vista do acabamento de um processo. Os fins, portanto, orientam todo o sistema educacional e determinam o tipo de homem que a educação procura formar. Já objetivo diz respeito aos meios através dos quais os fins serão realizados. Assim, os objetivos têm uma natureza instrumental, tendo-se em vista que estabelecem o modo através do qual os fins se concretizarão.

${ }^{9}$ Os autores Rizzi, Gonzalez e Ximenes (2011, p. 28) interpretam esse artigo como segue: “Aqui fica explícito o dever do Estado e o direito de todas as pessoas, sem qualquer distinção, com relação à educação. Também está definido que a família tem deveres (os pais e mães, por exemplo, são obrigados a matricular seus filhos e filhas na escola) e que a educação tem como objetivo o desenvolvimento integral da pessoa e a preparação para a inserção cidadã. O fato de a Constituição citar ainda a qualificação para o trabalho não significa ser esse seu objetivo principal, como muitas vezes se tenta interpretar. A educação profissional, para respeitar sua natureza de direito social constitucional, precisa estar integrada à concepção ampla de educação, possibilitando a inserção autônoma e qualificada no mundo do trabalho".
} 
Não se nega que as necessidades da vida e o avanço tecnológico exijam que as pessoas estejam cada vez mais qualificadas para o trabalho e que uma das formas de se conseguir isso é por meio da educação. No entanto, o desenvolvimento da pessoa implica muitas outras dimensões, principalmente o pleno desenvolvimento das capacidades humanas e o consequente preparo ao exercício da cidadania.

Além disso, é importante atentar para o fato de que a CRFB/88 refere-se basicamente à educação escolarizada, ao estabelecer a redação do artigo 206. Apoiando-se nos estudos de José Augusto Peres, Boaventura (1997, p. 146-7) elenca quatro razões para isso, a saber: (i) dificuldade de abordagem satisfatória da educação em sentido amplo; (ii) preocupação imediata com a escola; (iii) intangibilidade de muitos aspectos em que se desdobra a educação - por exemplo, a educação informal; e (iv) reconhecimento da importância social, política e econômica da instituição escolar e dos serviços por ela prestados. De fato, estas parecem razões suficientemente capazes de defender que o constituinte tinha em mente a educação, ainda que se reconheça que eles possam extrapolar o ensino.

Com efeito, vai-se, agora, brevemente observar o que cada um desses princípios ${ }^{10}$ preceitua concretamente à efetivação dos sistemas educacionais, no curso do qual se segue, nos seus aspectos mais gerais, as indicações de Rizzi, Gonzalez e Ximenes (2011, p. 37-9):

1) Igualdade de condições para o acesso e permanência na escola: afirma que não é permissível a existência de discriminações e que o Estado deve garantir as condições de acesso para que todos possam estudar, assim como reforça a necessidade de que se assegure um padrão nacional de qualidade em todas as escolas do país. Sobre isso, Boaventura reforça que o acesso ao ensino obrigatório e gratuito é direito público subjetivo e que, neste particular, o seu não-oferecimento importa, pelo Poder Público, responsabilidade da autoridade competente (BOAVENTURA, 1997, p. 148-9). ${ }^{11}$

2) Liberdade de aprender, ensinar, pesquisar e divulgar o pensamento, a arte e o saber: claramente vinculado à tradição liberal, uma vez que é um desdobramento do valor da

\footnotetext{
${ }^{10}$ Não se adentra na questão, de caráter hermenêutico e filosófico, sobre a distinção entre princípios e regras que se poderia encontrar especialmente no artigo 206 da CRFB/88. Mas, apesar de ela não ser relevante no contexto desta pesquisa, indica-se a compreensão desta discussão através de Ximenes (2014).

${ }^{11}$ Maliska faz uma discussão deste princípio a partir da teoria filosófica e constitucional, referindo-se a figuras como Kant, Bobbio, Dworkin e Canotilho. O autor tem em vista ponderar o significado da igualdade e da sua relação com a liberdade, especialmente nos termos do princípio da igualdade de oportunidades. Segundo esse autor, pelo menos à época em que a CRFB/88 foi promulgada, "o direito de iguais condições para o acesso e permanência na escola é, em parte, a constatação do constituinte de que o Brasil é um país em que muitas crianças estão fora da escola, de que é necessário instruí-las, de que é necessário dar oportunidades de estudo também àqueles que não a tiveram, na época adequada, enfim, tal direito é um instrumento de diminuição das desigualdades fáticas". Mais adiante, acrescenta que, vinculando instituições públicas e privadas, o princípio da igualdade de oportunidades "[...] implica no estabelecimento de critérios gerais e não discriminatórios" (MALISKA, 2001, p. 172-3). Importa referenciar, igualmente, que este princípio não é contraditório com a existência das políticas afirmativas, conforme ratificam as decisões do STF (duas delas, entre outras): (i) Arguição de Descumprimento de Preceito Fundamental (ADPF) nº. 186-DF, em que foi relator o Ministro Ricardo Lewandowski, em 2012; e (ii) Ação Direta de Inconstitucionalidade (ADI) no. 3.330-DF, em que foi relator o Ministro Ayres Britto.
} 
liberdade no terreno da educação, de um lado, é conexo com os princípios da liberdade de expressão e manifestação de pensamento, da liberdade de consciência e crença e da legalidade (LELLIS, 2013, p. 117) e, de outro, em termos de conteúdo, sustenta, aos docentes e aos estudantes, a liberdade de manifestar ideias e pensamentos em espaços de formação, tanto nas escolas públicas como nas privadas. ${ }^{12}$

3) Pluralismo de ideias e de concepções pedagógicas, e coexistência de instituições públicas e privadas de ensino: também em evidente relação com a perspectiva liberal, esse princípio afiança que os sistemas de ensino devem respeitar as diferentes concepções, sejam filosóficas, teóricas e pedagógicas, que o corpo docente, os estudantes, os pais e as escolas podem ter, bem como deixa aberta a possibilidade da existência de escolas privadas, desde que cumpram com as regras estabelecidas para sua criação e funcionamento. ${ }^{13}$

4) Gratuidade do ensino público em estabelecimentos oficiais: declara a gratuidade do ensino público, em todos os níveis e modalidades, prestado em estabelecimentos oficiais. Aqui é importante a distinção entre a educação, que está associada à cultura, como um todo, e pela qual Estado, família e sociedade são responsáveis, e o ensino, que se refere à atividade escolarizada e institucionalizada de conhecimento. Este princípio se refere estritamente ao ensino, não à educação. ${ }^{14}$

5) Valorização dos profissionais da educação escolar: estabelece a valorização dos profissionais da educação nos termos de planos de carreira específicos e a garantia de formação (inicial e em serviço), condições adequadas de trabalho e salário digno, bem

\footnotetext{
${ }^{12}$ Maliska ressalta também o caráter de circunscrição desse princípio, isto é, que ele é voltado à defesa da liberdade no âmbito das instituições acadêmicas. Nesse sentido, apoiando-se no Manual de Direito Constitucional, de Jorge Miranda, explica que a liberdade na escola ou a liberdade acadêmica significa, notadamente duas coisas: “[...] (i) a liberdade dos professores de ensino, de acordo com a procura da verdade, o seu saber, a sua orientação científica e pedagógica; (ii) o direito do aluno à compreensão crítica dos conteúdos do ensino" (MALISKA, 2001, p. 177).

${ }^{13} \mathrm{Na}$ sua dissertação de mestrado, Oyama se concentra particularmente sobre esse princípio da educação. Nesse sentido, a autora afirma que "O preceito constitucional do artigo 206, inciso III, significa que não cabe ao Estado impor modelos, ideias únicas e autoritárias a ser aplicadas no processo de ensino-aprendizagem, nem editar concepções pedagógicas, mas construídas no cotidiano das atividades educativas, respeitando as realidades regionais, as diferenças ideológicas, a autonomia das unidades escolares e o contexto social da localidade, desde que os princípios constitucionais sejam respeitados" (OYAMA, 2009, p. 152).

${ }^{14}$ A respeito deste princípio, o constitucionalista brasileiro José Afonso da Silva assim se expressa: "O princípio do art. 206, IV, significa que onde o ensino oficial, em qualquer nível, já é gratuito não poderá passar a ser pago. Onde é pago, se for educação básica, deverá passar a ser oferecido gratuitamente até 2016 (EC-59/2009, art. 62). Concretiza-se, assim, a promessa de se estender a gratuidade progressivamente até o ensino médio, que, como se sabe, hoje é uma etapa da educação básica. A gratuidade do ensino oficial nos três níveis - fundamental, médio e superior - é velha tradição do sistema educacional brasileiro. Pode-se, agora, dizer que essa tradição não era nada mais nada menos do que uma projeção futura, porquanto veio a ajustar-se à evolução que tornara a educação um serviço público integrante dos fins do Estado Democrático. Por isso é que a Constituição, acolhendo a evolução, elevara a educação à categoria de direito de todos e, correlativamente, à categoria de dever do Estado" (SILVA, 2014, p. 856).
} 
como promoção do reconhecimento da importância social da profissão docente e dos demais trabalhadores da educação. ${ }^{15}$

6) Gestão democrática do ensino público: determina, em primeiro lugar, que os profissionais da educação, os pais, mães e responsáveis legais, além dos próprios estudantes, devem participar da elaboração do projeto político pedagógico da escola, e que a comunidade tem o direito de participar nos conselhos escolares, e, em segundo lugar, que o sistema de ensino deve contar com espaços de participação social para a gestão democrática, como conselhos e conferências periódicas. ${ }^{16}$

7) Garantia de padrão de qualidade: estabelece que a educação pública precisa respeitar um padrão de qualidade definido nacionalmente, o qual deve assegurar, a todos os estudantes, condições semelhantes de aprendizado adequado, respeitando-se a diversidade de expectativas educacionais. Neste particular, este princípio reclama o oferecimento eficiente de instrução, de forma que "[...] o ensino deve ser um instrumento eficaz para que o aluno possa desenvolver-se plenamente como pessoa, restar qualificado para o trabalho e estar apto ao exercício da cidadania" (LELLIS, 2013, p. 122). ${ }^{17}$

8) Piso salarial profissional nacional para os profissionais da educação escolar pública: impõe a criação de um piso nacional de professores - o que se deu através da Lei 11.738/08 -, o qual deve estar associado à carreira dos profissionais do magistério, prevendo uma valorização efetiva, e que, também, precisa ser estendida aos demais trabalhadores da educação.

Estes princípios, portanto, traduzem-se em guias e pilares sobre os quais a educação, mas, sobretudo, o ensino deverá ser realizado dentro do território brasileiro. No entanto, destaca-se que, uma vez que o país professa a defesa de direitos, entre os quais se encontra a liberdade, pode-se dizer que, no âmbito da educação, a liberdade se desdobra particularmente na liberdade de ensino e

\footnotetext{
${ }^{15}$ Sobre este princípio, importa dizer que ele recebeu regramento específico, dado nos termos da Lei $n^{\circ} 11.738$, de 2008, e que está diretamente associado ao Piso Salarial Profissional Nacional para os Profissionais da Educação Escolar Pública.

${ }^{16}$ Mais especificamente, em obra individual, Ximenes fala sobre esse princípio. Para ele, "[...] a pluralidade é um componente da liberdade de ensino, delimitada, no âmbito do constitucionalismo democrático, por objetivos e valores educacionais que compõem o conteúdo amplo do direito à educação e que devem ser expressos nas diretrizes e bases, inclusive curriculares. O princípio da gestão democrática qualifica essa questão ao impor uma delimitação procedimental, que visa permitir a participação de professores, pais e estudantes na definição do projeto político-pedagógico das escolas e na participação na gestão de sua implementação. Tal participação, por sua vez, está diretamente conectada à dimensão de adaptabilidade do direito à educação [...]" (XIMENES, 2014, p. 196-7).

${ }^{17}$ Há que se valorizar o estimulante livro de Ximenes sobre essa temática e a sua proposta de que uma educação de qualidade, para fazer jus a esse princípio, deveria fundar-se sobre quatro pilares, a saber: (i) um nível mínimo de aquisição de conhecimentos, valores, capacidades e competências pelos estudantes; (ii) infraestrutura, instalações e ambientes escolares adequados; (iii) um corpo docente bem qualificado; e (iv) uma escola aberta à participação de todos (XIMENES, 2014, p. 390).
} 
no pluralismo de ideias e concepções pedagógicas - tanto para o professor, quanto para os alunos e suas famílias.

\subsection{A LIBERDADE DE ENSINO E O PLURALISMO DE CONCEPÇÕES E IDEIAS PEDAGÓGICAS}

Para dar atenção às características que distinguem os dois princípios, adotar-se-á, nesta seção, a abordagem separada da liberdade de ensino e do pluralismo de concepções e ideias pedagógicas.

\subsubsection{A Liberdade de Ensino}

A liberdade de ensino, em termos de um dos princípios constitucionais da atividade educativa, está prevista no artigo 206 da Constituição Federal de 1988. Também, no mesmo sentido, lê-se a pluralidade de ideias e concepções pedagógicas. Assim,

Art. 206 O ensino será ministrado com base nos seguintes princípios:

[...]

II - liberdade de aprender, ensinar, pesquisar e divulgar o pensamento, a arte e o saber;

III - pluralismo de idéias e de concepções pedagógicas, e coexistência de instituições públicas e privadas de ensino; (BRASIL, 1988).

O princípio da liberdade de ensinar, pesquisar e divulgar o pensamento, a arte e saber, como explica Motta, é uma continuidade e uma complementação lógica dos direitos e garantias fundamentais do homem - aqueles consagrados no Título II da CRFB/88. Nesse sentido, ao definir a liberdade de ensino como um princípio constitucional, o constituinte garantiu sua consequência lógica, a autonomia da escola e dos professores (liberdade de cátedra) e a livre atuação na área educacional para as instituições privadas (MOTTA, 1997, 172). Com efeito, a liberdade de ensino tem o seu escopo, especialmente, dado em quatro âmbitos, nestes termos:

(i) Liberdade de aprendizagem: a liberdade de aprendizagem, em verdade, caracteriza-se pela faculdade que têm os indivíduos de escolha diante dos diferentes modelos e concepções de aprendizagem. De fato, refere-se à liberdade que o indivíduo tem de aprender o que quer que seja, estando, desse ponto de vista, diretamente vinculada à liberdade de pensamento e de consciência. Há aqui o entendimento de que as ideias e as concepções pedagógicas não podem ser algo imposto. Por ela, vê-se que especialmente o professor não pode impor qualquer visão ou perspectiva pedagógica e educacional sobre aquelas que sejam oriundas do exercício da liberdade do estudante ou dos pais ou responsáveis. Deveras, como é o caso de todas as liberdades, não se trata de uma liberdade absoluta, pois que se deve dar dentro dos limites de um Estado de Direito Democrático: ela retira sua validade das forças políticas 
democráticas.

(ii) Liberdade de ensino: afeta diretamente os docentes, refere-se ao fato de que aqueles que estão envolvidos com atividades de ensino estejam a salvo das ingerências administrativas, inconstitucionais ou ilegais, preservando a busca e a comunicação da verdade da ciência, o que levará à eficiência do aprendizado. Dessa perspectiva, para realizar a eficiência do aprendizado, a liberdade de ensino será exercida dentro dos limites da exigência de qualidade do ensino, o que se traduz na obediência, em primeiro lugar, aos parâmetros curriculares, e, depois, à previsão de conteúdos mínimos instituídos pelo Estado e à avaliação da qualidade da instrução, entre outros (LELLIS, 2010, p. 242). Importa dizer, assim, que a liberdade de ensino também não é absoluta, uma vez que se deve realizar dentro dos limites da legalidade no limiar de um Estado constitucional, em matéria de educação. Com efeito, disso não se segue que se possa restringi-la pura e simplesmente: se ela não é absoluta, como se disse, também não é verdade que possa ser restrita conforme o sabor de interesses específicos, tendo-se em conta que ela é uma garantia da própria autonomia e capacidade para fazer escolhas que a posse de conhecimentos científicos e afins estabelece, em relação direta com a liberdade de pensamento e de consciência. Sem a liberdade de ensino, todo o envolvimento com qualquer mentalidade comprometida com o conhecimento ficaria padecida da falta de autonomia do pensar e da inventividade e criatividade que estão na base da ciência.

(iii) Liberdade de pesquisa: por ela, tem-se no horizonte “[...] as investigações científicas, exercidas por profissionais para a expansão das fronteiras do conhecimento e, acadêmica, dotada de fim didático, ou seja, de reforço da aprendizagem” (LELLIS, 2010, p. 242). De fato, a liberdade de pesquisa é um princípio elementar que estabelece a relevância da autonomia para o desenvolvimento da atividade de pesquisa. Mas ela não pode dar-se de qualquer forma: ela precisa revelar o compromisso do pesquisador com as técnicas, bem como o domínio daqueles elementos necessários afetos à pesquisa rigorosa e de alto nível. Assim, o pesquisador, no âmbito das atividades de ensino, não pode ser restringido em sua liberdade, a qual está radicada na posse dos conhecimentos vinculados a sua expertise, a sua competência técnica, de tal modo que não sofra impedimentos de outra natureza que não aqueles dos limites da própria lei.

(iv) Liberdade de divulgação: está diretamente relacionada à liberdade de ensino e de pesquisa, tendo em vista revela-se na divulgação dos resultados da pesquisa e do ensino. Assim, entende-se que a liberdade de divulgação está intimamente relacionada à liberdade de ensinar e de pesquisar, pois que sem essa relação, não há o que divulgar. 
A despeito deste princípio da liberdade de ensino, é preciso reforçar que ele é, como liberdade, uma via de mão dupla: assiste tanto ao professor quanto aos alunos e pais. E isso porque justamente não se baseia numa imposição, mas numa prerrogativa individual, isto é, uma faculdade do sujeito. No entanto, em função das restrições da lei, ele tem um conteúdo político, que são justamente aqueles da ordem política e legal constituída no Estado Democrático de Direito.

Do exposto acima, fica claro que a liberdade de ensino não comporta uma decisão unilateral, tendo em vista que a imposição fere o caráter democrático do ensino. Conforme explicam Donadeli e Gonçalves, o docente deve tratar o aluno consoante a sua singularidade, no curso do qual tem liberdade para decidir sobre o que ensinar, respeitando as normas e regras vigentes, sejam as da União, estados e municípios, sejam as da escola, nos termos de seus projetos políticos pedagógicos.

A liberdade de ensinar não deve ser confundida com autoritarismo. O docente deve ter autoridade dentro da sala, mas isso não implica poder usar de meios que ferem o bom senso e a dignidade do aluno. A autoridade é uma forma de impor respeito sem ser rude ou grosseiro. O respeito não é algo que se impõe, mas que se conquista dia-a-dia, através de uma relação de confiança e afetividade. O docente deve estabelecer as normas e discutir com os alunos, debatendo um compromisso ético, visando chegar a um ponto comum, bom para as duas partes, docente e discente (DONADELI \& GONÇALVES, 2006).

A liberdade de ensino é, assim, uma prática de liberdade: respeita a liberdade do estudante e do professor, fazendo jus à autoridade que institucionalmente possui, seja ela a do cargo, seja a que o diploma confere, de modo a poder agir com autonomia didático-científica. Por isso, como expõem Rodrigues e Marocco:

A liberdade de ensinar não protege, entretanto, as manifestações valorativas, ideológicas e religiosas que desrespeitem a liberdade de consciência dos alunos e que não possuam correlação com a matéria ensinada, bem como aquelas que professem preconceitos e discriminações vedadas pela nossa ordem constitucional e legal.

E, também, mais para frente, afirmam:

De outro lado, a liberdade de ensinar autoriza o professor a utilizar métodos, metodologias, estratégias e instrumentos à sua escolha, dentre aqueles legalmente e pedagogicamente autorizados e reconhecidos [...]. Neste contexto, além das escolhas mais propriamente ligadas à didática - tipo de aula e de atividades, recursos tecnológicos, etc. - , está também incluída a liberdade de escolha de textos e obras, desde que contenham o conteúdo a ser ministrado e, no seu conjunto, permitam o acesso ao pluralismo de ideias presente no campo específico do conhecimento, e que não contenham material que endosse preconceitos e discriminações (RODRIGUES \& MAROCCO, 2014, p. 224).

Como se percebe, a liberdade de ensinar do professor está voltada à educação, isto é, àquela atividade que deve levar ao pleno desenvolvimento da pessoa, o seu preparo para a cidadania e a sua qualificação para o trabalho (art. 205, CRFB/88). Dessa forma, a liberdade de ensinar é indissociada da liberdade de aprender. Não se concebe a liberdade de ensino separadamente daquela que é a sua causa de existir: levar o estudante ao aprendizado, no interior de um conjunto de saberes 
sobre o qual instituições de ensino chancelam a posse dos conhecimentos necessários para a atividade pedagógica. Assim, a liberdade de ensino e a liberdade de aprender se referem a "[...] direitos e liberdade umbilicalmente ligados" (RODRIGUES \& MAROCCO, 2014, p. 225). ${ }^{18}$

\subsubsection{O Pluralismo de Concepções e Ideias Pedagógicas}

Por sua vez, o princípio do pluralismo de ideias e de concepções pedagógicas - que preceitua também a coexistência de instituições públicas e privadas de ensino ${ }^{19}$ - estabelece a multiplicidade de concepções e ideias pedagógicas. Por esta posição, o constituinte tem em mente que, no interior das instituições de ensino, não há a hegemonia de uma concepção apenas, mas a abertura às diferentes posições, pensamentos ou concepções pedagógicas e educacionais de professores, alunos e demais envolvidos no processo educacional, nos diversos níveis e domínios da formação, os quais podem ser de ordem teórica, filosófica, religiosa ou doutrinária.

Por certo, o pluralismo de ideias e concepções pedagógicas traduz a ideia, no Estado Democrático de Direito Constitucional, de que não cabe a ele, Estado, impor modelos, concepções e perspectivas a serem aplicados no processo de formação, particularmente, no processo de ensinoaprendizagem, mas respeitar as diferenças que constituem, de um lado, os agentes propriamente da educação, a saber, professores, alunos e demais envolvidos, e, de outro, as diferentes realidades e contextos regionais e sociais característicos do Brasil. Assim, por este princípio, deve o Estado respeitar as diferenças de convicções pedagógicas e ideológicas que se manifestam na educação que, evidentemente, não se oponham a ordem legal vigente -, as características regionais e locais, bem como a autonomia das unidades escolares e institucionais de educação.

Como se nota, o pluralismo de ideias e concepções pedagógicas é consoante os valores democráticos, reforçando alguns pontos elementares, tais como a tolerância e a diversidade, conquanto reconhecer que as pessoas possam ser levadas à constituição de diferentes perspectivas quanto aos valores que arvoram o processo pedagógico. Por isso, como vaticina Messeder, a palavra-chave que o norteia e o enriquece é a heterogeneidade:

Aspectos ideológicos de natureza cultural, filosóficos, profissionais, pedagógicos, de forma criteriosa e nunca leviana, devem ser levados em conta na organização da instituição escolar. Perceba que este princípio, assim como todos os outros, não aplicável apenas à célula (sala de aula), e sim a todo o organismo (escola). (MESSEDER, 2007, p. 46).

\footnotetext{
${ }^{18}$ Como acréscimo, seguindo a explicação de Rodrigues e Marocco, indica-se que a liberdade de ensinar garante às instituições de ensino que, cumpridas as normas gerais da educação e as diretrizes curriculares, possam livremente construir seus projetos pedagógicos, evidentemente, permanecendo ainda submetidas a processos avaliativos por parte do poder público, de forma que os critérios adotados para aferir a qualidade vinculam tanto as instituições como seus docentes (RODRIGUES \& MAROCCO, 2014, p. 214-5).

${ }^{19}$ Para os propósitos desse artigo, não se avançará na discussão desta questão.
} 
Ora, reforça-se que sem o pluralismo de ideias e concepções pedagógicas não existe algo como uma educação consoante ao Estado Democrático de Direito: é preciso respeitar os diferentes pontos de vista e opiniões de agentes e atores da educação. Por isso, vale a referência ao que explica Golschmidt:

\begin{abstract}
A convivência numa sociedade efetivamente democrática pressupõe que os homens aceitem e respeitem as suas diferenças, ou seja, admitam que nem todos pensam da mesma forma e que nem todos veem do mesmo modo as coisas do mundo. É justamente a aceitação e o respeito a esse pluralismo de ideias, calcado no princípio da reciprocidade, que permite o convívio social e o exercício das liberdades individuais; o pluralismo de concepções pedagógicas é o corolário do pluralismo de ideias. De fato, nem todos os educadores possuem a mesma concepção pedagógica, e nem poderá ser diferente, pelo simples fato de que nem todos os educandos são iguais e nem todos desafiam o mesmo método ou estratégia de ensino (GOLSCHMIDT, 2003, p. 58).
\end{abstract}

Na próxima seção, apontar-se-ão os valores políticos com os quais, no Estado Democrático de Direito, a educação está comprometida. Trata-se, assim, do conteúdo político da educação nacional.

\title{
3. O CONTEÚDO POLÍTICO DA EDUCAÇÃO
}

Falou-se, até aqui, da natureza social da educação, da relação com a liberdade e dos princípios constitucionais da educação, com particular atenção à liberdade de ensino e à pluralidade de ideias e concepções pedagógicas. O que se pretende agora é apresentar o conteúdo político da educação nacional, de forma a estabelecer que, por força de determinação legal, toda a educação praticada no cenário nacional está vinculada a certos valores políticos irrenunciáveis.

Como se sabe, a CRFB/88 está comprometida com valores políticos da tradição ocidental. Observa-se, já no preâmbulo, quando o legislador constituinte originário, representando o povo, afirma o seu propósito, ele o faz em referência à instituição de um Estado Democrático, o qual é:

[...] destinado a assegurar o exercício dos direitos sociais e individuais, a liberdade, a segurança, o bem-estar, o desenvolvimento, a igualdade e a justiça como valores supremos de uma sociedade fraterna, pluralista e sem preconceitos, fundada na harmonia social e comprometida, na ordem interna e internacional, com a solução pacífica das controvérsias [...] (BRASIL, Preâmbulo, 1988).

É evidente o entendimento de que esses valores políticos devem orientar toda a leitura e interpretação, tanto da própria Constituição, como das leis complementares e ordinárias a ela relacionadas, já que neles estão as bases sobre as quais os princípios e normas constitucionais foram alicerçados - inclusive os princípios constitucionais educacionais. E, segundo o que Motta indica, esses valores políticos são o ponto de partida e a bússola de todo o conteúdo da educação nacional, a qual não pode ser entendida "[...] de maneira simplista, como um mero instrumento de reprodução 
infalível e automático da ideologia da classe dominante [...]. Se a educação não pode ser concebida como um mecanismo de manipulação, também é verdade que não pode ser vista como como algo neutro. Inegavelmente, a educação tem o seu conteúdo político e, às vezes, até ideológico e partidário [...]" (MOTTA, 1997, p. 155). Como este autor evidencia, o caráter político que deve acompanhar todo o processo educativo, em território pátrio, está descrito na própria CRFB/88, nos termos dos cinco fundamentos que enumera o artigo $1^{\circ}$, in verbis:

Art. $1^{\circ}$. A República Federativa do Brasil, formada pela união indissolúvel dos Estados e Municípios e do Distrito Federal, constitui-se em Estado democrático de direito e tem como fundamentos:

I - a soberania;

II - a cidadania;

III - a dignidade da pessoa humana;

IV - os valores sociais do trabalho e da livre iniciativa;

$\mathrm{V}$ - o pluralismo político.

Parágrafo único. Todo o poder emana do povo, que o exerce por meio de representantes eleitos ou diretamente, nos termos desta Constituição (BRASIL, 1988).

Estes fundamentos devem ser compreendidos como valores essenciais que compõem a estrutura de um Estado, tendo um duplo papel: de um lado, indiretamente, eles atuam como diretriz para a elaboração, interpretação e aplicação de outras normas do ordenamento jurídico; de outro lado, diretamente, são utilizados como razões para a decisão de um caso concreto (NOVELINO, 2016, p. 250). ${ }^{20}$ No entanto, esse conteúdo político da educação brasileira é completado com os objetivos constantes no artigo $3^{\circ}$, a saber:

Art. $3^{\circ}$. Constituem objetivos fundamentais da República Federativa do Brasil: I - construir uma sociedade livre, justa e solidária;

II - garantir o desenvolvimento nacional;

III - erradicar a pobreza e a marginalização e reduzir as desigualdades sociais e regionais;

IV - promover o bem de todos, sem preconceitos de origem, raça, sexo, cor, idade e quaisquer outras formas de discriminação (BRASIL, 1988).

Tanto os fundamentos como os objetivos da República Federativa do Brasil, e do Estado de Direito Democrático que a constitui, são, pois, reminiscentes do que se espera que o país seja, indicando, em toda lei e política os valores a serem promovidos e respeitados. E, como tal, dizem respeito também à educação. Nesse sentido, o disposto nos três primeiros artigos da CRFB/88, configura-se, no que até aqui se viu, no conteúdo político da educação. Mas interessa, agora, saber o modo como estes valores se relacionam com a liberdade de ensino, de forma que qualquer

\footnotetext{
${ }^{20}$ Vale ressaltar, como indica esse constitucionalista, que "apesar de esses princípios fundamentais não possuírem qualquer tipo de hierarquia normativa em relação às demais normas constitucionais, o elevado grau axiológico de que são dotados e a posição de destaque atribuída pelo Poder Constituinte Originário conferem peso elevado às razões por eles fornecidas, a ser considerado diante de eventual colisão com outros princípios constitucionais" (NOVELINO, 2016, p. 250). Em relação aos princípios constitucionais educacionais, que mais a frente serão vistos, significa apontar os indicadores de quais direções dever-se-á tomar, quando de um conflito ou da colisão de princípios educacionais.
} 
proposta que queira desvincular a educação dos valores políticos é, desde o princípio, inconstitucional e falha, pois que ela é constitutivamente impregnada de valores políticos da ordem constitucional. ${ }^{21}$

\subsection{A LIBERDADE DE ENSINO E O SEU CONTEÚDO POLÍTICO}

Do exposto, claro está que a educação, tal como praticada pelas instituições de ensino em território nacional, tem uma forte vinculação com os valores políticos - dados nos termos do art. $1^{\circ}$ e $3^{\circ}$ da CRFB/88. Como princípio da educação, a liberdade de ensino não pode ser usada para descategorizar este conteúdo político. Veja-se que todos os princípios constitucionais, inclusos os educacionais, estão estabelecidos com o claro propósito de permitir o exercício dos direitos individuais e sociais, através de um Estado Democrático de Direito: não há como negar a existência desses valores políticos para a ordem constitucional, especialmente, para as atividades educacionais e pedagógicas.

Particularmente, no tocante à liberdade de ensino, tanto as instituições de ensino como os seus docentes, demais profissionais e, inclusive, os alunos, devem compreender que existe uma base política que deve nortear a sua atividade. Quando se pensa num projeto, por exemplo, num projeto de lei como o Escola sem Partido ${ }^{22}$, que busca cercear a liberdade de ensino, fica claro o desrespeito aos valores políticos que devem orientar a atividade educativa. Como se viu, as bases da liberdade de ensino se justificam na direção do processo de aprendizagem, sem perder de vista os fundamentos políticos que a transpassam. Por isso, não se deve olvidar da importante questão posta por Frigotto sobre esse projeto - e outros que se pretendam levantar nesse vetor:

O que propugna o Escola sem Partido não liquida somente a função docente, no que a define substantivamente e que não se reduz a ensinar o que está em manuais ou apostilas, cujo propósito é de formar consumidores. A função docente no ato de ensinar tem implícito o ato de educar. Trata-se de, pelo confronto de visões de mundo, de concepções científicas e de métodos pedagógicos, desenvolver a capacidade de ler criticamente a realidade e constituírem-se sujeitos autônomos. A pedagogia da confiança e do diálogo crítico é substituída pelo estabelecimento de uma nova função: estimular os alunos e seus pais a se tornarem delatores (FRIGOTTO, 2017b, p. 31).

\footnotetext{
${ }^{21}$ Cumpre dizer, a título de informação, que a legislação infraconstitucional, sobretudo a Lei de Diretrizes e Bases da Educação Nacional, de 1996, vincula especialmente o conteúdo político da educação nacional àqueles aspectos que caracterizam a cidadania. É esse, por exemplo, o teor dos artigos $2^{\circ}, 22,32$ e 35 da LDBEN/96, que estabelece, no horizonte da formação, de algum modo, elementos que se traduzem no preparo para o exercício da cidadania. ${ }^{22}$ O Programa Escola Sem Partido, que deu origem ao Projeto de Lei no 867/2015, na câmara dos deputados, e que no senado recebeu a seguinte numeração, Projeto de Lei do Senado n ${ }^{\circ} 193$, de 2016, foi um projeto de lei que objetivava incluir entre as diretrizes da educação nacional uma série de postulados que afetavam, de forma negativa (criminalizava ações de professores), diretamente a atividade docente e a prática escolar. Sobre essa questão, o entendimento é formulado a partir de Frigotto (2017a), que reúne uma série de textos que discutem pontos elementares da questão.
} 
Observe-se que a premissa básica é justamente esta: sendo a liberdade de ensino um dos princípios constitucionais da educação, como um desdobramento do grande princípio da liberdade, ela está voltada à realização dos objetivos da ordem constitucional democrática e da educação que lhe é correspondente. A liberdade de ensino está umbilicalmente associada a fundamentos políticos, de forma que não há uma liberdade absoluta, avessa à discussão política. O que há, independentemente dos pressupostos e concepções que, através da liberdade de ensino valem-se os professores e demais imbrincados no processo de ensino-aprendizagem, é o respeito às bases políticas que arvoram a ordem constitucional. O processo de ensino-aprendizagem não pode se furtar à discussão dos seus fundamentos, das suas origens e das tensões mediantes as quais veio à lume. Mais do que isso: não pode o professor e demais envolvidos na educação, especialmente pais e responsáveis, impedirem que tais discussões sejam travadas, pois, assim, impedir-se-ia que o pleno desenvolvimento da pessoa, o seu preparo para o exercício da cidadania, bem como a sua qualificação para o trabalho (art. 205, CRFB/88) fosse realizado de forma crítica e ponderada.

Ao falar do projeto Escola sem Partido, Frigotto (2017b, p. 17-34) alude àqueles elementos que compõem o princípio da liberdade de ensino (art. 206, II, CRFB/88). Sem essa liberdade, sequer é possível pensar na pluralidade de ideias e concepções pedagógicas (art. 206, III, CRFB/88). A liberdade pressupõe a vivência com o diferente, inclusive, com os opostos, com os quais não se concorde ou se dê anuência, conquanto promover a tolerância. Por isso, em defesa da liberdade, convém ter em conta o que um pensador liberal, como John Rawls, disse sobre o papel da educação no liberalismo político. Segundo ele,

A preocupação da sociedade com a educação [das crianças] reside em seu papel de futuros cidadãos e, por conseguinte em coisas essenciais tais como a aquisição da capacidade de entender a cultura pública e de participar de suas instituições, de serem economicamente independentes e membros autônomos da sociedade ao longo de toda a sua vida, e de desenvolverem as virtudes políticas, tudo isso de um ponto de vista político (RAWLS, 2016, p. 249).

Evidentemente, para esse pensador, a educação, num regime constitucional, não pode ser apoiada sobre nenhuma doutrina abrangente, isto é, sobre concepções morais, filosóficas, doutrinárias, religiosas, que não sejam tolerantes para com as demais. E isso porque, se algo assim fosse feito, ter-se-ia a violação das condições de justificação pública às quais devem se referir os cidadãos quando discutem sobre as suas instituições, assim como as razões que possam ser mutuamente aceitáveis à luz dos princípios compartilhados - o que está dado, analogamente, no caso brasileiro, especialmente nos termos da CRFB/88.

A liberdade de ensino, neste viés, não reforça nenhuma visão particular sobre uma dimensão ontológica do conhecimento que não tenha respaldo na expertise que professa o docente, respeitando-se a pluralidade de concepções pedagógicas. Ademais, guiados por este princípio, os docentes não podem se esquivar à discussão política, uma vez que há fundamentos políticos que 
independem das concepções morais, religiosas e doutrinárias dos pais e que devem ser conhecidos. A liberdade de ensino, assim, não pode ser engessada sob pena de comprometerem-se os pilares políticos da ordem constitucional democrática vigente.

\section{CONSIDERAÇÕES FINAIS}

Cabe salientar que, em sociedades tão plurais, como é o caso da brasileira, a liberdade de ensino garante que a educação não seja tutelada por certas concepções de bem, sejam elas morais, filosóficas, doutrinárias e mesmo científicas sobre todas as demais. Como um dos traços característicos da atividade educativa, a liberdade de ensino assegura que o professor, valendo-se da sua expertise, também conferida por uma instituição de ensino, permite que o professor, de modo a se evitar o autoritarismo, decida por aquelas estratégias, tanto para o aprendizado quanto para a avaliação, que sejam mais pertinentes para o perfil do aluno e para o contexto social que o professor tem diante de si. No final das contas, a liberdade de ensino é uma garantia para o professor, para o aluno e para a sociedade em geral de que o professor agirá com a independência que o seu ofício requer. Trata-se, assim, da defesa da pluralidade de ideias e concepções pedagógicas, que surgem das diferentes atividades vinculadas à educação em razão da liberdade de ensino.

Com efeito, buscou-se propor, neste texto, uma discussão consistente que possa confrontar o caráter supostamente neutro, em matéria política, da prática da educação e das atividades pedagógicas desde a perspectiva da CRFB/88. Desta feita, defendeu-se, por meio de um rol de argumentos, que a educação é um direito de natureza social estando, contudo, vinculado à liberdade, uma vez que, numa via de mão dupla, de um lado, na prática da educação, os direitos e liberdades fundamentais se fazem presentes e, de outro, muitos deles dependem da educação para sua fruição.

Também, discutiu-se a finalidade da educação bem como, de forma breve, os princípios constitucionais que a guiam. Particularmente, no tocante a essa questão, deu-se especial atenção aos princípios da liberdade de ensino e ao pluralismo de concepções e ideias pedagógicas. A liberdade de ensino é um prolongamento dos direitos e liberdades fundamentais e uma garantia aos envolvidos no processo educacional contra ingerências e autoritarismos de qualquer ordem que impedem que uma educação genuinamente democrática possa ser desenvolvida. No mesmo sentido, defendeu-se que o pluralismo de ideias e concepções pedagógicas realiza a perspectiva de que, num Estado Democrático de Direito Constitucional, não se pode impor um modelo ou uma concepção sobre os demais, de forma hegemônica, determinando a maneira através do qual se dá o processo formativo.

Em seguida a isso, apresentou-se o conteúdo político da educação nacional, não de modo a ser um mero mecanismo de reprodução simplista e ideológico, mas, antes, nestes termos, de forma a não ser neutra - tendo em vista que muitas vezes, inclusive, esse conteúdo estabelece certo 
partidarismo. Esse conteúdo político, não obstante, está posto especialmente nos artigos $1^{\circ}$ e $3^{\circ}$ da CRFB/88, vale dizer, constituindo-se num Estado Democrático de Direito, (i) a soberania; (ii) a cidadania; (iii) a dignidade da pessoa humana; (iv) os valores sociais do trabalho e da livre iniciativa; (V) o pluralismo político, com o propósito de (a) construir uma sociedade livre, justa e solidária; (b) garantir o desenvolvimento nacional; (c) erradicar a pobreza e a marginalização e reduzir as desigualdades sociais e regionais; e (d) promover o bem de todos, sem preconceitos de origem, raça, sexo, cor, idade e quaisquer outras formas de discriminação (art. $1^{\circ}$ e $3, \mathrm{CRFB} / 88$ ). Traduzindo-se no conteúdo político da educação nacional, defendeu-se que estes valores exigem um compromisso ativo por parte das instituições de ensino e educacionais em território nacional.

$\mathrm{Na}$ última parte do texto, finalmente, fez-se uma conexão especialmente entre esse conteúdo político e a liberdade de ensino - ainda que, incidentalmente também se fale da pluralidade de ideias e concepções pedagógicas. Em relação a isso, buscou-se evidenciar que os projetos que cerceiam a liberdade docente, além de negarem os valores políticos da educação, prestam um desserviço às instituições dessa seara. Em contrapartida, valendo-se das ideias de Rawls, vaticinou-se que a educação deve ter em vista o papel de cada um como futuro cidadão, de tal sorte a desenvolver a capacidade de entender a cultura política de sua sociedade, bem como participar das suas instituições, de se tornarem economicamente independentes e membros autônomos dessa mesma sociedade (RAWLS, 2016, p. 249). Fazendo isso, espera-se não apenas reforçar o vínculo da educação com os valores políticos, rompendo, no marco legal, com o discurso de neutralidade na educação, mas também advogar na direção de que, sem a liberdade de ensino, expressando a pluralidade de ideias e concepções pedagógicas, ficam comprometidos os pilares do Estado Democrático de Direito.

\section{REFERÊNCIAS BIBLIOGRÁFICAS}

BOAVENTURA, Edvaldo. A Educação Brasileira e o Direito. Belo Horizonte: Nova Alvorada, 1997.

BOBBIO, Norberto. A Era dos Direitos. Rio de Janeiro: Elsevier, 2004.

BRASIL. Constituição da República Federativa do Brasil de 1988. Disponível em: http://www.planalto.gov.br/ccivil_03/constituicao/constituicao.htm. Acessado em: 17/01/18.

Lei $\mathbf{n}^{0}$ 9.394, de 20 de dezembro de 1996 - Lei de Diretrizes e Bases da Educação Nacional. Disponível em: http://www.planalto.gov.br/ccivil_03/LEIS/19394.htm. Acessado em 22/02/18.

Supremo Tribunal Federal. Argüição de Descumprimento de Preceito Fundamental

$\mathbf{n}^{\mathbf{0}}$ 186. Voto do Relator: Ministro Ricardo Lewandowski. Brasília-DF. Julgamento: 25 e 
26/04/2012.

Disponível

em:

http://stf.jus.br/portal/processo/verProcessoAndamento.asp?incidente=2691269. Acesso em: 23/01/19.

Projeto de Lei $\mathbf{n}^{\mathbf{8}} \mathbf{8 6 7}$ de 2015. Disponível em: <http://www.camara.gov.br/sileg/integras/1317168.pdf>. Acessado em: 10 jan. 2019.

Ficha de Tramitação - Escola sem Partido. Disponível em: <http://www.camara.gov.br/proposicoesWeb/fichadetramitacao?idProposicao=1050668/>. Acessado em: 10/01/2018.

CURY, Carlos R. J. Legislação Educacional Brasileira. Rio de Janeiro: DP\&A, 2000.

Por um novo Plano Nacional de Educação. Cadernos de Pesquisa (Fundação Carlos Chagas. Impresso), v. 41, p. 792-813, 2011.

DONADELI, Paulo Henrique Miotto; GONÇALVES, Viviane. Liberdade de Ensinar do Docente no Ensino Superior. Port.Pravda.Ru, 2006. Disponível em: $<$ http://port.pravda.ru/sociedade/cultura/13-07-2006/11952-ensino-0/>. Acesso em 08/01/19.

FRIGOTTO, Gaudêncio (Org.). Escola "sem" partido. Esfinge que ameaça a educação e a sociedade brasileira. Rio de Janeiro: LPP- UERJ, 2017a.

A Gênese das Teses do Escola sem partido: esfinge e ovo de serpente que ameaça a sociedade e a educação. In: FRIGOTTO, Gaudêncio (Org.). Escola "sem" Partido. Esfinge que ameaça a educação e a sociedade brasileira. Rio de Janeiro: LPP- UERJ, 2017 b.

GOLDSCHMIDT, Rodrigo. O Princípio da Proporcionalidade no Direito Educacional. Passo Fundo: UPF, 2003.

LELLIS, Lélio M. O Direito Fundamental à Educação Configurado pelos Princípios do Ensino. Cadernos de Direito (UNIMEP), v. 13, p. 103-131, 2013.

MALISKA, Marcos A. O Direito à Educação e a Constituição. Porto Alegre: Sérgio Antônio Fabris Editor, 2001.

MESSEDER, Hamurabi. LDB: Lei de Diretrizes e Bases da Educação Nacional: Lei no 9.394/96 com mais de 500 questões de provas anteriores. Rio de Janeiro: Elsevier, 2007 (série Provas e Concursos).

MORAES, Alexandre. Direito Constitucional. São Paulo: Saraiva, 2002.

MOTTA, E. O. Direito Educacional e Educação no Século XXI. Brasília: Unesco, 1997.

NAGIB, Miguel. Escola Sem Partido: Educação sem Doutrinação. 2019. Disponível em: <http://www.escolasempartido.org/quem-somos/>. Acesso em: 10 jan. 2019.

NOVELINO, Marcelo. Curso de Direito Constitucional. $11^{\text {a }}$ Ed. Salvador: Editora JusPodivm, 2016.

OYAMA, Lurdes K. A Educação na Constituição de 1988: o Processo Educacional e a Educação Contemporânea. Dissertação (Mestrado) - Curso de Direito, Pontifícia Universidade Católica de São Paulo, Puc/sp, Brasil., São Paulo, 2009. 
RAWLS, John. O Liberalismo Político. São Paulo: Saraiva, 2016.

RIZZI, Ester; GONZALEZ, Marina; XIMENES, Salomão B. Direito Humano à Educação. 2a . ed. Curitiba/São Paulo: Plataforma Dhesca Brasil/Ação Educativa, 2011.

RODRIGUES, Horácio W.; \& MAROCCO, Andréa A. L. Liberdade de cátedra e a Constituição Federal de 1988: alcance e limites da autonomia docente. In: CAÚLA, B.; MARTINS, D.; ARAÚJO E MENDONÇA, M.; CARMO, V. (Org.). Diálogo Ambiental, Constitucional e Internacional. Fortaleza, CE: Premius, 2014, v. 2, p. 213-238.

SARLET, Ingo Wolfgang. Os Direitos Fundamentais Sociais na Constituição de 1988. In: PIOVSAN, F; GARCIA, Marcia (Org.). Doutrinas Essenciais Direitos Humanos. São Paulo/SP: Editora Revista dos Tribunais, 2011, v. III, p. 639-676.

. Os Direitos Sociais como Direitos Fundamentais no âmbito da Constituição Federal. In: Narciso leandro Xavier Baez; Rogério Luiz Nery da Silva; Guido Smorto. (Org.). Os desafios dos Direitos Humanos Fundamentais na América Latina e na Europa. 1ed.Joaçaba/SC: Editora Unoesc, 2012, v. 01, p. 471-512.

SILVA, José Afonso. Curso de Direito Constitucional Positivo. $38^{\mathrm{a}}$ Ed. São Paulo: Malheiro Editores, 2014.

TEIXEIRA, Anísio. Educação não é Privilégio. São Paulo: Companhia Ed. Nacional, 1971.

XIMENES, Salomão B. Direito à Qualidade na Educação Básica: Teoria e Crítica. São Paulo: Quartier Latin, 2014.

Trabalho recebido em 10 de maio de 2020 Aceito em 04 de setembro de 2021 